\title{
PIK3CA-AKT Pathway Predominantly Acts in Developing Ipsilateral Breast Tumor Recurrence Long After Breast Conserving Surgery
}

Hiroshi Nakagomi ( $\sim$ h-nakagomi@ych.pref.yamanashi.jp )

Yamanashi Prefecture Central Hospital: Yamanashi Kenritsu Chuo Byoin https://orcid.org/0000-00020068-4487

\section{Masayuki Inoue}

Yamanashi Prefecture Central Hospital: Yamanashi Kenritsu Chuo Byoin

\section{Yosuke Hirotsu}

Yamanashi Prefecture Central Hospital: Yamanashi Kenritsu Chuo Byoin

\section{Kenji Amemiya}

Yamanashi Prefecture Central Hospital: Yamanashi Kenritsu Chuo Byoin

Hitoshi Mochiduki

Yamanashi Prefecture Central Hospital: Yamanashi Kenritsu Chuo Byoin

\section{Masao Omata}

Yamanashi Prefecture Central Hospital: Yamanashi Kenritsu Chuo Byoin

\section{Research Article}

Keywords: Ipsilateral Breast Tumor Recurrence (IBTR), Genome Profiling, PIK3CA-AKT pathway, Breast Conserving Surgery

Posted Date: February 21st, 2022

DOl: https://doi.org/10.21203/rs.3.rs-1310576/v2

License: (c) (1) This work is licensed under a Creative Commons Attribution 4.0 International License. Read Full License

Version of Record: A version of this preprint was published at Breast Cancer Research and Treatment on March 25th, 2022. See the published version at https://doi.org/10.1007/s10549-022-06570-y. 


\section{Abstract}

Purpose: Ipsilateral Breast Tumor Recurrence (IBTR) after breast-conserving therapy is seen after a long interval, but the clinical classification of Residual Tumor Recurrence (RR) or Double Primary (DP) needs to be validated. We used genome profiling to identify the genetic alterations associated with IBTR.

Methods: Among 1,881 breast cancer patients treated with breast-conserving therapy between 1999 and 2018, IBTR occurred in 52 patients (2.8\%). Of these 22 patients who consented for genomic analysis of Primary Breast Cancer ( T1) and IBTR (T2) were studied. When the same gene mutations in T1 and T2 were identified, it was classified as genomic residual recurrence gRR, and when no shared mutations identified, it was classified as gDP. The differences between clinical and genomic classification were compared. Furthermore, the pathway of the genes which were responsible for recurrence was also examined.

Results: Of 13 clinically diagnosed RRs (cRRs), 11 were gRR and 2 were gDPs, while of 9 cDPs, 6 were gDP and $3 \mathrm{gRR}$, with a match rate of $17 / 22$ (77\%). We searched for genes involved in IBTR: PIK3CAAKT pathway mutations were found in 12 of $14 \mathrm{gRRs}(86 \%)$ in T1, and only 2 of $8 \mathrm{gDPs}(25 \%)$ with significant difference $(p=0.004)$. When both of PBC and IBTR compared, PIK3CA-AKT pathway abnormalities were $24 / 28(86 \%)$ in the gRR and 5/16 (31\%) in the gDP $(p<0.001)$.

Conclusions: Genome profiling revealed that abnormalities in the PIK3CA-AKT pathway in long-term residential recurrences and are a crucial molecular group in the development of IBTR.

Trial registration: not applicable

\section{Introduction}

Breast-conserving therapy (BCT), a combination of breast-conserving surgery (BCS) followed by wholebreast irradiation, is an established standard therapy for early-stage breast cancer. Many clinical trials with subsequent meta-analyses have provided clear evidence that BCT achieves a long-term survival equivalent to mastectomy [10,33]. Initially, local recurrence (LR) rate after BCS was reported $6-11 \%$ in 5 years and $10-13 \%$ in 10 years [9]. Improvement of diagnostic modality for the extent of tumor spread and optimal treatment by radiation and adjuvant chemotherapies have obviously contributed to the decrease of LR rate [6].

However, LR still have occurred $1-5 \%$ in 10 years [21, 32]. In addition, a question still remains whether this ipsilateral breast tumor recurrence (IBTR) is a true recurrence of the residual primary tumor or clonally different new primaries. Furthermore, the clonal nature of IBTR after radiation and adjuvant therapy has not been fully elucidated by genomic analysis.

The aim of this study is to reveal the genomic profiling of IBTR which developed after BCT in long-term interval of $7.7 \pm 4.6$ years (ranging 0.9 to 19.7 ). We believe this analysis may present new insight into the 
nature of "recurrence" by revealing their genome profiles.

\section{Methods}

\section{Selection of patients with IBTR for clinical and genomic analysis}

A total of 2,770 patients with breast cancer underwent surgery from 1999 to 2018 in our hospital; total mastectomy in 889 patients (32\%) and breast conserving surgery (BCS) in 1,881 (68\%) (Fig. 1). After BCS, $98 \%$ of patients were treated by irradiation of $50 \mathrm{~Gy}$ for whole breast and in cases with residual tumor found at margin of resected specimen had additional $10 \mathrm{~Gy}$ for the tumor bed. Furthermore, adjuvant systemic therapies were added according to the guidelines [1] [2] . Of 1,881 cases with BCS, the ipsilateral breast tumor recurrence (IBTR) had developed in $52(2.8 \%)$ cases with median follow of $7.7 \pm$ 4.6 years (ranging 0.9 to 19.7 years).

We reviewed clinical features including age at developing PBC, TNM classifications, stage, histology, immunohistochemical subtypes and interval years from PBC to IBTR (Table 1). Among the 52 cases with IBTR, written informed consent for genomic analysis was obtained in 22 cases. We analyzed genomic profile of paired samples of primary breast cancer (PBC or T1) and recurrence (IBTR or T2) (Fig. 2 a, b).

\section{Clinically defined residual recurrence (RR) and double primaries (DP)}

First, we classified those IBTR whether they are clinical residual recurrence (cRR) of the primary tumors or de novo double primaries (CDP) according to the following gross anatomical and microscopic features. Gross anatomical concordance (AC) was judged, whether the IBTR developed in the same quadrant of the index lesion of PBC [23] .

Histological concordance $(\mathrm{HC})$ was judged by the similarity of pathological findings and immunohistochemical subtypes between the PBC and IBTR [20]. We judged IBTR as clinical residual recurrence (CRR) by belonging to both of $A C$ and $\mathrm{HC}$ and the others were judged as clinical double primaries (CDP).

\section{Genomically defined residual recurrence (gRR) and double primaries (gDP)}

We classified IBTR into two groups by genome profiling, namely, genomic residual recurrence (gRR) and genomic double primary (gDP) by cancer panel analysis $[14,16,17,28]$. We defined gRR by the existence of identical mutations, especially driver oncogenic mutations, in both tissue of PBC and IBTR, whereas gDP was defined by the absence of shared mutations in both tissues. Correlations of clinically and genomically defined cRR/cDP and gRR/gDP were studied.

\section{Genome analysis of primary breast cancer and IBTR ( 22 cases)}

\section{Preparation of samples}


The tumor samples from PBC and IBTR were obtained from surgical resections or biopsies. A serial section of 10- $\mu \mathrm{m}$-thick, formalin-fixed and paraffin-embedded (FFPE) tissue was stained with haematoxylin-eosin and then microdissected using an Arcturus XT laser-capture microdissection system (Thermo Fisher Scientific, Waltham, MA, USA) [15].

Peripheral blood samples were obtained and buffy coats were isolated following centrifugation of peripheral blood at $820 \mathrm{I} \mathrm{g}$ at $25^{\circ} \mathrm{C}$ for $10 \mathrm{~min}$, and subsequently stored at $-80^{\circ} \mathrm{C}$ until required for DNA extraction. Total DNA was extracted from lymphocytes using the QIAamp DNA blood mini QIAcube kit (Qiagen, Hilden, Germany). The concentration of DNA was determined using a Nano Drop 2000 spectrophotometer (Thermo Fisher Scientific, Waltham, MA, USA).

\section{${ }^{15}$ Targeted deep sequencing}

For targeted deep sequencing analysis, as we previously reported [19], Ion AmpliSeq designer (Thermo Fisher Scientific) was used to design custom primers, which consisted of 2,863 primer pairs in two pools [4]. These primers covered the exons of 53 breast cancer-associated genes (total 287,520 nucleotides) reported by the TCGA project, other studies, and the COSMIC database $[3,11,29]$ (sTable 1).

Multiplex polymerase chain reaction (PCR) was performed with Ion AmpliSeq Library Kit Plus and two primer pools, as we previously described [18]. The library concentration was determined by quantitative real-time PCR using an Ion Library Quantitation Kit. Emulsion PCR and chip loading were performed on the lon Chef with the Ion PI Hi-Q Chef kit. Sequencing was performed on the lon Proton Sequencer (Thermo Fisher Scientific).

\section{Data analysis}

The sequencing data were processed using standard lon Torrent Suite software running on a Torrent Server as described previously [19]. Variants calling and annotations were performed using an lon Reporter Server System, and peripheral blood DNA was used as a control to detect variants in tumours using filtration of "confident somatic variants" in a Tumour-Normal pair pipeline. The minimum count for mutant allele reads was more than 10 and coverage depth was more than 20 . Common single nucleotide polymorphisms were excluded from further analysis.

\section{Annotation of the genome profiling}

We compared genome profiling of paired samples of PBC and IBTR.

The significant mutated gene (SMG) which was defined with allelic fraction more than $1 \%$ and the number of driver genes were defined according to the oncoKB (Precision Oncology Knowledge Database, Memorial Sloan Kettering Cancer Center, USA) .

\section{Elucidation of driver gene and pathway to promote recurrence}


We tried to elucidate whether any genes and pathways which might be significantly altered might play an important role for the development of recurrences after many years.

\section{Statistical Analysis}

Statistical analysis was performed by $\mathrm{t}$ test or $\chi^{2}$ test as appropriate using Stat Mate (Atoms, Tokyo, Japan).

\section{Results}

\section{Clinical Features of 1,881 BCS, 52 total IBTR and DNA analyzed 22 IBTR}

When comparing the clinical features of all 1,881 patients who underwent breast-conserving surgery and 52 patients who developed IBTR, there were no differences in age, TNM classification, presence of lymph node metastasis, histological type, or immunohistochemical subtypes (Table 1). The clinical features of the 52 patients with IBTR and the 22 patients whose genomic profiles were analyzed showed a difference in age of $54 \pm 12$ vs. $47 \pm 9$ ( $p=0.01$ ), but no difference in TNM classification, histology, or immune subtype (Table 1). The clinical classification of cRR and CDP was 40:12 and 13:9 in all 52 IBTR cases and 22 genomically analyzed cases, respectively $(p=0.12)$ (Table 1$)$.

\section{Comparison of clinical (cRR/cDP) and genomic (gRR/gDP) judgement}

The 22 genomically analyzed cases were classified as gRR (genomic residual recurrence) and gDP (genomic double primary) (Fig. $2 \mathrm{a}, \mathrm{b}$ ). As a result, 14 cases were classified as the former and 8 cases as the latter. Three of 14 gRRs (gRR4, gRR6, and gRR7, Fig.2a) were classified as cDP. The reason for three cases judged as CDP was that the recurrent IBTR was not in the same quadrant. Regarding 8 genomically judged double primaries, two (gDP1 and gDP2) were judged as clinical residual recurrence (cRR) because they were in the same quadrant and histologically consistent (Fi g. 2b). In short, the agreement between clinical and genomic profile was 17/22 (77\%) and the disagreement was 5/22 (23\%) (Fig. 1, 2 a, b). Clinical judgement heavily related on the location of IBTR which might have limited the accuracy of the discerption.

\section{Intervals and pattern of recurrence}

Next, we examined the interval to recurrence and the presence of distant metastasis in 14 patients with gRR (Table 2a) and 8 patients with gDP (Table $2 b$ ). The time to IBTR for gRR and gDP was $7.5 \pm 3.7$ (range 2.7-14.2) and 9.9 \pm 4.3 (3.3-16.5) years, with no significant difference between the two groups $(p=0.21)$ (Table 1). Five of the 14 patients (36\%) with gRR were found to have recurrence after more than 10 years (Table 2a). In addition, the presence of distant metastasis was found in 4 of 14 RRs (28\%), but not in $8 \mathrm{gDPs}$ (Table 2a, 2b). These results suggest that the recurrence of gRR is unique in that it can occur over a period of more than 10 years with systemic metastasis. 
We examined the immunohistological subtype (HR pos. Her2 pos. Both. neg.) in the gRR and gDP groups (Tables $2 \mathrm{a}, \mathrm{b}$ ). In all 14 cases of gRR, the same subtype, i.e., 11 HR pos. and 3 Her2 pos. cases was observed (Table 2a). On the other hand, in 3 of $8 \mathrm{gDP}$ cases, the HR pos. at the time of first occurrence (PBC) changed to Both neg. in IBTR (Table 2b).

\section{Genome Profiling of gRR and gDP}

First, we compared the number of oncogenic mutations in the PBC (T1) and in the IBTR (T2) in the two groups (Table 3).

Regarding oncogenic mutations in PBC (T1) they were 2.2 \pm 1.6 and $1.3 \pm 0.7$ in $\mathrm{gRR}$ and in gDP, respectively, $(p=0.11)$. The mutations in IBTR (T2) were 1.7 \pm 0.8 and $1.0 \pm 0.6(p=0.06)$ in $g R R$ and gDP, respectively (Table 3 ). The difference were not statistically significant. However, when the total number of mutations of PBC and of IBTR were combined, more oncogenic mutations were found in $\mathrm{gRR}$ than in $\operatorname{gDP}(2.0 \pm 1.3$ vs $1.2 \pm 0.8)(p=0.03)($ Table 3$)$.

\section{Significance of PIK3CA-AKT pathway}

We then sorted the individual oncogenic mutations into signaling pathways and compared the two groups. The number of cases with mutations in the PIK3CA-AKT pathway in PBC (T1) was significantly higher in the gRR group; gRR 12/14 (86\%) and gDP 2/8 (25\%), respectively $(p=0.004)$ (Table 3). This PIK3CA-AKT pathway abnormality persisted in IBTR (T2); 12/14 (86\%) in gRR group ( $p=0.02)$. In gDP group, 3 cases (gDP3, gDP4, gDP5) showed PIK3CA-AKT pathways abnormality were seen in IBTR (T2), but none of them preexisted in PBC (T1) (Table 3). Both PBC and IBTR combined, abnormality in PIK3CAAKT pathway in the gRR group apparent with strong statistical significance $(p<0.001)$ (Table 3$)$.

In addition, individual genetic mutations in the PIK3CA-AKT signal pathway were identified. PIK3CA mutations were found in 8/14 (57\%) of the PBCs in the gRR group, of which PIK3CA p. His1047Arg accounted for 4 cases (Fig.2a). In addition, two cases of AKT mutations and two cases of PTEN mutations were observed, which were mutually exclusive with the occurrence of PIK3CA mutations (Table $2 \mathrm{a})$. On the other hand, in PBC (T1) of gDP, PIK3CA mutation was found in only one case (13\%), and there were no $A K T$ and PTEN mutations (Table $2 \mathrm{~b}$ ).

TP53/Cell cycle/DNA damage pathway mutations were significantly higher in T1 with gRR 6/14 cases (43\%) vs gDP $0 / 8(0 \%)(p=0.03)$, but not in T2 with gRR 5/14 (36\%) vs gDP 2/8 (30\%) ( $p=0.6)$. When both combined (T1+T2), gRR showed tendency to have higher abnormality $(11 / 28(39 \%)$ vs $2 / 16(13 \%))$, but the difference did not reach statistical significance $(p=0.06)$ (Table 3$)$.

As an additional finding, there was one case of invasive lobular carcinoma (gRR7) among 22 cases. The resected margins of PBC were pathologically confirmed as free, and IBTR occurred in different quadrants after a 6-year interval. Therefore, they were clinically judged as double primaries (Fig. 2a). However, they had four identical mutations ( $A K T, C D H 1, K M T 2 C$ and FOXA 1) and genomically defied as gRR, (Fig. 2a, Table 2a). 


\section{Discussion}

In 20 years from 1999 to 2018 , we surgically treated 2,770 patients with breast cancer, of which 1,881 (68\%) underwent breast-conserving therapy (BCT). During the same period, we have experienced only 52 cases of recurrence within the conserved breast (2.3\%), which is not a high frequency, as the 10-year IBTR has been reported to be $1-5 \%[21,32]$. However, because of the preservation of breast tissue, it was extremely important to determine whether the recurrence was due to "leftover" or new cancer.

Conventional clinical judgment has been based on whether PBC and IBTR were in the same quadrant and whether they were histologically similar. In this study, we first followed these criteria $[20,23]$. It was previously reported that the percentage of RR cases was higher, while interval was longer and prognosis was better in DP cases, ${ }^{22,23}$. In this study, 52 patients with a mean follow-up of 7.7 years (0.9-19.7 years) more cases were judged as CRR (40) than CDP (12 cases), consistent with previous data.

In several different organs, we had previously examined the concordance between primary and metastatic sites in lung and gastric cancers using deep sequencing of tumor tissues $[14,16,17,28]$. We have also reported the usefulness of panel sequencing in differentiating intrahepatic metastases from multiple metastases in liver [19], lung [14], and gastric cancer [17]. In this study, we applied this method to IBTR.

Both PBC and IBTR were analyzed in twenty-two patients who consented to genome analysis. These 22 cases were genomically classified into $14 \mathrm{gRR}$ and $8 \mathrm{gDP}$. The probability of agreement with clinical classification was 77\%, and the probability of disagreement was 23\% (Fig. 2 a, b).

There are only a few scattered reports that have confirmed RR and DP by molecular biological methods. Vicini et al. compared clonality by looking at the loss-of-heterogeneity in microsatellite lesions and found that $30 \%$ of cases had a discrepancy with clinical classification [34]. This report also showed that DP had a longer interval and better prognosis than RR, as in other reports [20, 27]. In addition, Bollet et al. reported similar results using chromozome copy number alteration to detect clonality [5]. However, there have been no reports of analysis using NGS deep panel sequencing to explore the underlying mechanism of IBTR.

Our 22 patients were classified into $14 \mathrm{gRR}$ and $8 \mathrm{gDP}$. There was no difference in the interval between gRR and gDP (7.5 \pm 3.7 vs. $9.9 \pm 4.3)(p=0.21)$. In fact, 5 cases $(36 \%)$ in the gRR group developed IBTR over 10 years, and the longest gRR case (gRR14) was observed in 14 years. All patients received radiation therapy for IBTR prevention and adjuvant therapy according to the guidelines. Since, it is thought that the treatment tolerant persister cells survived and caused IBTR in hormonal therapy, in particular, for longterm (5 to 10 years). However, previous studies had limitations that there were few cases with more than 10 years of follow-up.

The cancer panel deep sequencing revealed not only clonality, but also the genome profile of treatmentresistant tissue that lead to recurrence. In our study, we found that persisters with mutations in the 
PIK3CA-AKT pathway were more likely to have recurrent disease. In other words, $12 / 16$ (86\%) of gRR cases were associated with mutations in the PIK3CA-AKT pathway.

$24,252829,303132$ PIK3CA mutations are most common in breast cancer, with a frequency of $30-40 \%$ in HR pos. and Her2 Pos. subtypes [7]. It is an important mutation involved in oncogenesis, cell proliferation, invasion, and resistance to treatment, and is attracting attention as a therapeutic target $[24,26]$. In particular, the mutations are found in the early stages of carcinogenesis and are associated with the development of various types of cancer [31]. The hot spot mutation, PIK3CA pHis1047Arg, is reported to be a multipotential genetic change that appears early in the development of breast cancer and progresses to various types of breast cancer [22]. Interestingly, this hot spot mutations were identified in PBC (T1) 5 of 14 cases and all belong to g RR group (Fig.2a). Among these 5 gRRs, 3 (gRR11, gRR13, gRR 14) persisted over 10 years (Fig.2a). It has been reported that PIK3CA mutations were clinically observed not only in invasive carcinoma but also in surrounding intraductal lesions [25]. In addition, AKT1 mutations have been reported to be associated with breast cancer stem cells [12], although the rate is not high at $3 \%$ of breast cancers [7] . These reports suggest that persisters with PIK3CA-AKT pathway mutations in intraductal breast lesions are resistant to radiation and other therapies, resulting in IBTR, for over 10 years.

Additionally, in one ILC cases (gRR7), a group of cells with mutations in AKT, CDH1, FOXA1 and KMT2C persisted and developed IBTR after 6 years. This is a group of genes that has been shown in several studies as the genome profile of ILC $[8,13]$.

The limitation of this study is that the cases we were able to retrieve with consent were mainly HR pos. with only 3 Her2 pos. cases, and we were not able to analyze Both neg. cases. Her2 pos. and Both neg. cases tend to have a shorter time to recurrence clinically, and majority of cases were judged as RR. The majority of patients who were able to obtain IC were those who developed IBTR as late recurrence, resulting in a majority of HR pos. From another point of view, we were able to show the characteristics of late recurrence of breast cancer, that is resistant to treatment, and persisted and hidden in the body in a state of dormancy for a long period and has recurred [30]

\section{Conclusion}

The deep panel sequencing is a useful method to differentiate between RR and DP in IBTR. In addition, the genome profile of treatment-resistant persisters after breast-conserving therapy was found to have mutations in the PIK3CA-AKT pathway. The application of this interesting biological property to therapy is a future challenge which may including HR therapy over ten years for patients with hot spot mutations such as PIK3CA H1047Arg.

\section{Declarations}


Funding: This study was supported by the Japan Society for the Promotion of Science (JSPS) KAKENHI Grant-in-Aid for Scientific Research (B) (Grant Number $20 \mathrm{H} 03668$ to YH), Early-Career Scientists (Grant Number JP18K16292 to YH), and Research Grant for Young Scholars (to YH), the YASUDA Medical Foundation (to $\mathrm{YH}$ ), the Uehara Memorial Foundation (to $\mathrm{YH}$ ), the Medical Research Grants from the Takeda Science Foundation (to YH), and a Grant-in-Aid for Genome Research Project from Yamanashi Prefecture (to $\mathrm{MO}$ and $\mathrm{YH}$ ).

Competing interests: The authors declare that they have no competing interest.

\section{Authors contribution:}

All Authors contributed to the study conception and design. Material collection and data collectionwere performed by Hiroshi Nakagomi, Masayuki Inoue and analysis were performed by Yosuke Hirotsu, Kenji Amemiya and Hitoshi Mochiduki. The first draft of the manuscript was written by Hiroshi Nakagomi and Masao Omata, and all authors commented on previous version of the manuscript

Ethics approval and consent to participant: This study was approved by the institutional review board in our hospital (No.2018-6). We analyzed 22 cases in whom written informed consent for genomic analysis was obtained.

Consent for publication: Consent for publication was included in the written informed consent.

Availability of data and materials: The datasets analyzed during current study are available from the corresponding author on reasonable request.

Acknowledgement: not applicable.

\section{References}

1. National Comprehensive Cancer Network. available at https://www.nccn.org/store/login/login.aspx? ReturnURL=https://www.nccn.org/professionals/physician_gls/pdf/breast.pdf accessed 29,Jan. 2022.

2. Guidelines of Japanese Breast Cancer society. available at https://jbcs.gr.jp/guidline/2018/index/ accessed 29, Jan, 2022.

3. (2012) Comprehensive molecular portraits of human breast tumours. Nature 490:61-70. doi: 10.1038/nature11412nature11412 [pii]

4. Amemiya K, Hirotsu Y, Goto T, Nakagomi H, Mochizuki H, Oyama T, Omata M (2016) Touch imprint cytology with massively parallel sequencing (TIC-seq): a simple and rapid method to snapshot genetic alterations in tumors. Cancer Med 5:3426-3436. doi: 10.1002/cam4.950

5. Bollet MA, Servant N, Neuvial P, Decraene C, Lebigot I, Meyniel JP, De Rycke Y, Savignoni A, Rigaill G, Hupe P, Fourquet A, Sigal-Zafrani B, Barillot E, Thiery JP (2008) High-resolution mapping of DNA 
breakpoints to define true recurrences among ipsilateral breast cancers. J Natl Cancer Inst 100:48-58. doi: 10.1093/jnci/djm266

6. Bosma SC, van der Leij F, van Werkhoven E, Bartelink H, Wesseling J, Linn S, Rutgers EJ, van de Vijver MJ, Elkhuizen PH (2016) Very low local recurrence rates after breast-conserving therapy: analysis of 8485 patients treated over a 28-year period. Breast Cancer Res Treat 156:391-400. doi: $10.1007 /$ s10549-016-3732-0

7. Cancer Genome Atlas N (2012) Comprehensive molecular portraits of human breast tumours. Nature 490:61-70. doi: 10.1038/nature11412

8. Ciriello G, Gatza ML, Beck AH, Wilkerson MD, Rhie SK, Pastore A, Zhang H, McLellan M, Yau C, Kandoth C, Bowlby R, Shen H, Hayat S, Fieldhouse R, Lester SC, Tse GM, Factor RE, Collins LC, Allison $\mathrm{KH}$, Chen YY, Jensen K, Johnson NB, Oesterreich S, Mills GB, Cherniack AD, Robertson G, Benz C, Sander C, Laird PW, Hoadley KA, King TA, Network TR, Perou CM (2015) Comprehensive Molecular Portraits of Invasive Lobular Breast Cancer. Cell 163:506-519. doi: 10.1016/j.cell.2015.09.033

9. Clarke M, Collins R, Darby S, Davies C, Elphinstone P, Evans V, Godwin J, Gray R, Hicks C, James S, MacKinnon E, McGale P, McHugh T, Peto R, Taylor C, Wang Y, Early Breast Cancer Trialists' Collaborative $\mathrm{G}$ (2005) Effects of radiotherapy and of differences in the extent of surgery for early breast cancer on local recurrence and 15-year survival: an overview of the randomised trials. Lancet 366:2087-2106. doi: 10.1016/S0140-6736(05)67887-7

10. Fisher B, Bauer M, Margolese R, Poisson R, Pilch Y, Redmond C, Fisher E, Wolmark N, Deutsch M, Montague $\mathrm{E}$, et al. (1985) Five-year results of a randomized clinical trial comparing total mastectomy and segmental mastectomy with or without radiation in the treatment of breast cancer. $\mathrm{N}$ Engl $\mathrm{J}$ Med 312:665-673. doi: 10.1056/NEJM198503143121101

11. Forbes SA, Beare D, Gunasekaran P, Leung K, Bindal N, Boutselakis H, Ding M, Bamford S, Cole C, Ward S, Kok CY, Jia M, De T, Teague JW, Stratton MR, McDermott U, Campbell PJ (2015) COSMIC: exploring the world's knowledge of somatic mutations in human cancer. Nucleic Acids Res 43:D805811. doi: $10.1093 /$ nar/gku1075

12. Gener P, Rafael D, Seras-Franzoso J, Perez A, Pindado LA, Casas G, Arango D, Fernandez Y, DiazRiascos ZV, Abasolo I, Schwartz S, Jr. (2019) Pivotal Role of AKT2 during Dynamic Phenotypic Change of Breast Cancer Stem Cells. Cancers (Basel) 11. doi: 10.3390/cancers11081058

13. Ginter PS, D'Alfonso TM (2017) Current Concepts in Diagnosis, Molecular Features, and Management of Lobular Carcinoma In Situ of the Breast With a Discussion of Morphologic Variants. Arch Pathol Lab Med 141:1668-1678. doi: 10.5858/arpa.2016-0421-RA

14. Goto T, Hirotsu Y, Mochizuki H, Nakagomi T, Shikata D, Yokoyama Y, Oyama T, Amemiya K, Okimoto K, Omata M (2017) Mutational analysis of multiple lung cancers: Discrimination between primary and metastatic lung cancers by genomic profile. Oncotarget 8:31133-31143. doi:

10.18632/oncotarget.16096

15. Goto T, Hirotsu Y, Oyama T, Amemiya K, Omata M (2016) Analysis of tumor-derived DNA in plasma and bone marrow fluid in lung cancer patients. Med Oncol 33:29. 
16. Higuchi R, Nakagomi T, Goto T, Hirotsu Y, Shikata D, Yokoyama Y, Otake S, Amemiya K, Oyama T, Mochizuki H, Omata M (2020) Identification of Clonality through Genomic Profile Analysis in Multiple Lung Cancers. J Clin Med 9. doi: 10.3390/jcm9020573

17. Hirotsu Y, Hada M, Amemiya K, Oyama T, Mochizuki H, Omata M (2020) Multi-regional sequencing reveals clonal and polyclonal seeding from primary tumor to metastases in advanced gastric cancer. J Gastroenterol 55:553-564. doi: 10.1007/s00535-019-01659-6

18. Hirotsu Y, Nakagomi H, Sakamoto I, Amemiya K, Oyama T, Mochizuki H, Omata M (2015) Multigene panel analysis identified germline mutations of DNA repair genes in breast and ovarian cancer. Mol Genet Genomic Med 3:459-466.

19. Hirotsu Y, Zheng TH, Amemiya K, Mochizuki H, Guleng B, Omata M (2016) Targeted and exome sequencing identified somatic mutations in hepatocellular carcinoma. Hepatol Res 5:12663.

20. Huang E, Buchholz TA, Meric F, Krishnamurthy S, Mirza NQ, Ames FC, Feig BW, Kuerer HM, Ross MI, Singletary SE, McNeese MD, Strom EA, Hunt KK (2002) Classifying local disease recurrences after breast conservation therapy based on location and histology: new primary tumors have more favorable outcomes than true local disease recurrences. Cancer 95:2059-2067. doi:

10.1002/cncr.10952

21. Ishitobi M, Komoike Y, Motomura K, Koyama H, Inaji H (2010) Early response to neo-adjuvant chemotherapy in carcinoma of the breast predicts both successful breast-conserving surgery and decreased risk of ipsilateral breast tumor recurrence. Breast J 16:9-13. doi: 10.1111/j.15244741.2009.00864.x

22. Koren S, Reavie L, Couto JP, De Silva D, Stadler MB, Roloff T, Britschgi A, Eichlisberger T, Kohler H, Aina O, Cardiff RD, Bentires-Alj M (2015) PIK3CA(H1047R) induces multipotency and multi-lineage mammary tumours. Nature 525:114-118. doi: 10.1038/nature14669

23. Krauss DJ, Kestin LL, Mitchell C, Martinez AA, Vicini FA (2004) Changes in temporal patterns of local failure after breast-conserving therapy and their prognostic implications. Int J Radiat Oncol Biol Phys 60:731-740. doi: 10.1016/j.jijobp.2004.04.010

24. Li H, Prever L, Hirsch E, Gulluni F (2021) Targeting PI3K/AKT/mTOR Signaling Pathway in Breast Cancer. Cancers (Basel) 13. doi: 10.3390/cancers13143517

25. Lin CY, Vennam S, Purington N, Lin E, Varma S, Han S, Desa M, Seto T, Wang NJ, Stehr H, Troxell ML, Kurian AW, West RB (2019) Genomic landscape of ductal carcinoma in situ and association with progression. Breast Cancer Res Treat 178:307-316. doi: 10.1007/s10549-019-05401-x

26. Mosele F, Stefanovska B, Lusque A, Tran Dien A, Garberis I, Droin N, Le Tourneau C, Sablin MP, Lacroix L, Enrico D, Miran I, Jovelet C, Bieche I, Soria JC, Bertucci F, Bonnefoi H, Campone M, Dalenc F, Bachelot T, Jacquet A, Jimenez M, Andre F (2020) Outcome and molecular landscape of patients with PIK3CA-mutated metastatic breast cancer. Ann Oncol 31:377-386. doi:

10.1016/j.annonc.2019.11.006

27. Sun GY, Wang SL, Tang Y, Jin J, Song YW, Liu YP, Wang WH, Fang H, Chen SY, Ren H, Liu XF, Yu ZH, Li YX (2018) [Clinical characteristics and prognosis of patients with ipsilateral breast tumor recurrence 
after breast conservation therapy]. Zhonghua Zhong Liu Za Zhi 40:352-358. doi:

10.3760/cma.j.issn.0253-3766.2018.05.007

28. Takano A, Hirotsu Y, Amemiya K, Nakagomi H, Oishi N, Oyama T, Mochizuki H, Omata M (2017) Genetic basis of a common tumor origin in the development of pancreatic mixed acinarneuroendocrine-ductal carcinoma: A case report. Oncol Lett 14:4428-4432. doi: 10.3892/ol.2017.6786

29. Toy W, Shen Y, Won H, Green B, Sakr RA, Will M, Li Z, Gala K, Fanning S, King TA, Hudis C, Chen D, Taran T, Hortobagyi G, Greene G, Berger M, Baselga J, Chandarlapaty S (2013) ESR1 ligand-binding domain mutations in hormone-resistant breast cancer. Nat Genet 45:1439-1445. doi: $10.1038 / \mathrm{ng} .2822$

30. Vallette FM, Olivier C, Lezot F, Oliver L, Cochonneau D, Lalier L, Cartron PF, Heymann D (2019) Dormant, quiescent, tolerant and persister cells: Four synonyms for the same target in cancer. Biochem Pharmacol 162:169-176. doi: 10.1016/j.bcp.2018.11.004

31. Van Keymeulen A, Lee MY, Ousset M, Brohee S, Rorive S, Giraddi RR, Wuidart A, Bouvencourt G, Dubois C, Salmon I, Sotiriou C, Phillips WA, Blanpain C (2015) Reactivation of multipotency by oncogenic PIK3CA induces breast tumour heterogeneity. Nature 525:119-123. doi: 10.1038/nature14665

32. van Laar C, van der Sangen MJ, Poortmans PM, Nieuwenhuijzen GA, Roukema JA, Roumen RM, Tjan-Heijnen VC, Voogd AC (2013) Local recurrence following breast-conserving treatment in women aged 40 years or younger: trends in risk and the impact on prognosis in a population-based cohort of 1143 patients. Eur J Cancer 49:3093-3101. doi: 10.1016/j.ejca.2013.05.030

33. Veronesi U, Saccozzi R, Del Vecchio M, Banfi A, Clemente C, De Lena M, Gallus G, Greco M, Luini A, Marubini E, Muscolino G, Rilke F, Salvadori B, Zecchini A, Zucali R (1981) Comparing radical mastectomy with quadrantectomy, axillary dissection, and radiotherapy in patients with small cancers of the breast. N Engl J Med 305:6-11. doi: 10.1056/NEJM198107023050102

34. Vicini FA, Antonucci JV, Goldstein N, Wallace M, Kestin L, Krauss D, Kunzmann J, Gilbert S, Schell S (2007) The use of molecular assays to establish definitively the clonality of ipsilateral breast tumor recurrences and patterns of in-breast failure in patients with early-stage breast cancer treated with breast-conserving therapy. Cancer 109:1264-1272. doi: 10.1002/cncr.22529

\section{Tables}

Tables are available in Supplementary Files Section.

\section{Figures}


Fig. 1

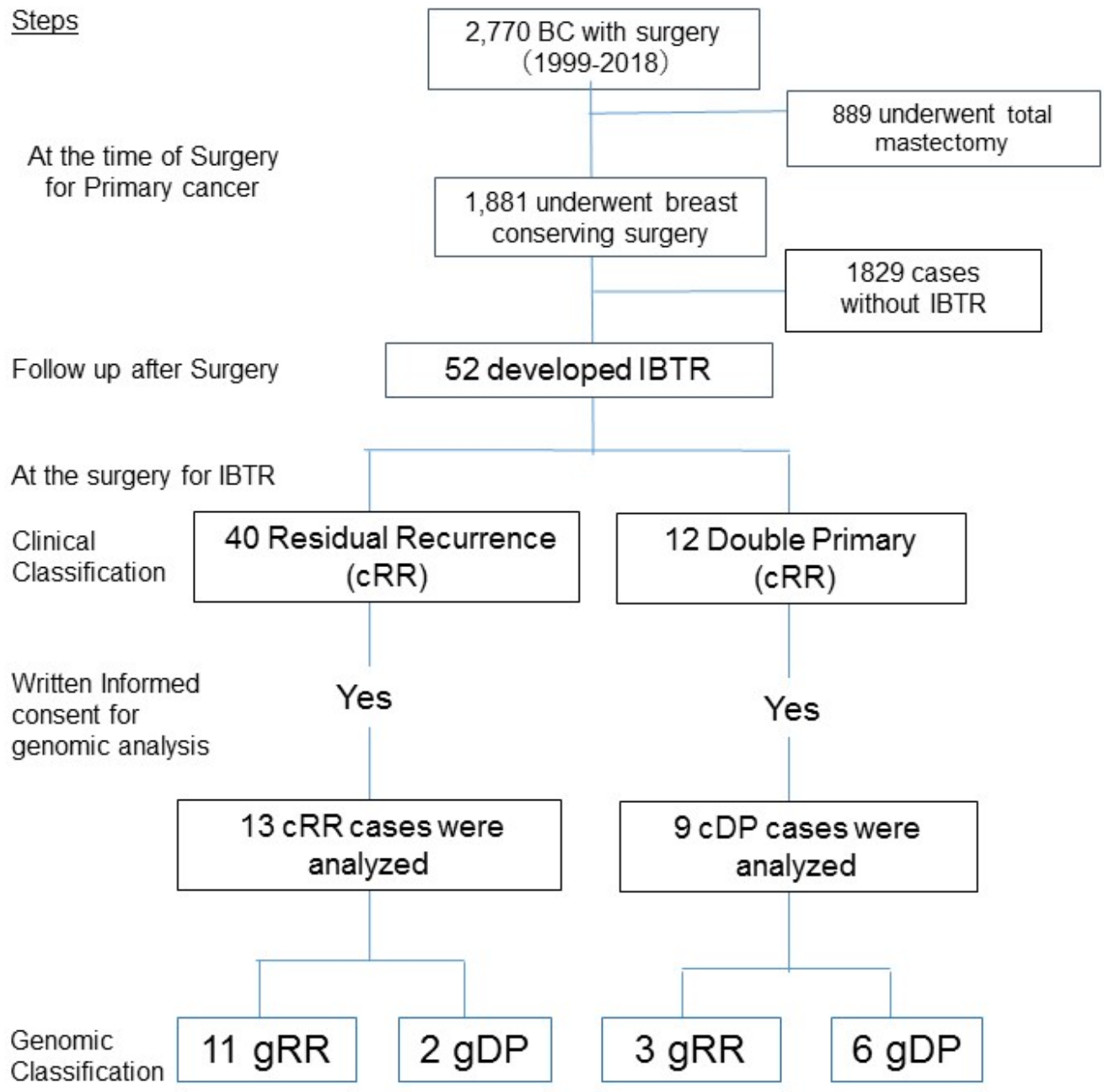

\section{Figure 1}

Flow chart of 2,770 patients with breast cancer to study clinical and genomic features for Ipsilateral Breast Tumor Recurrence 
Fig.2a

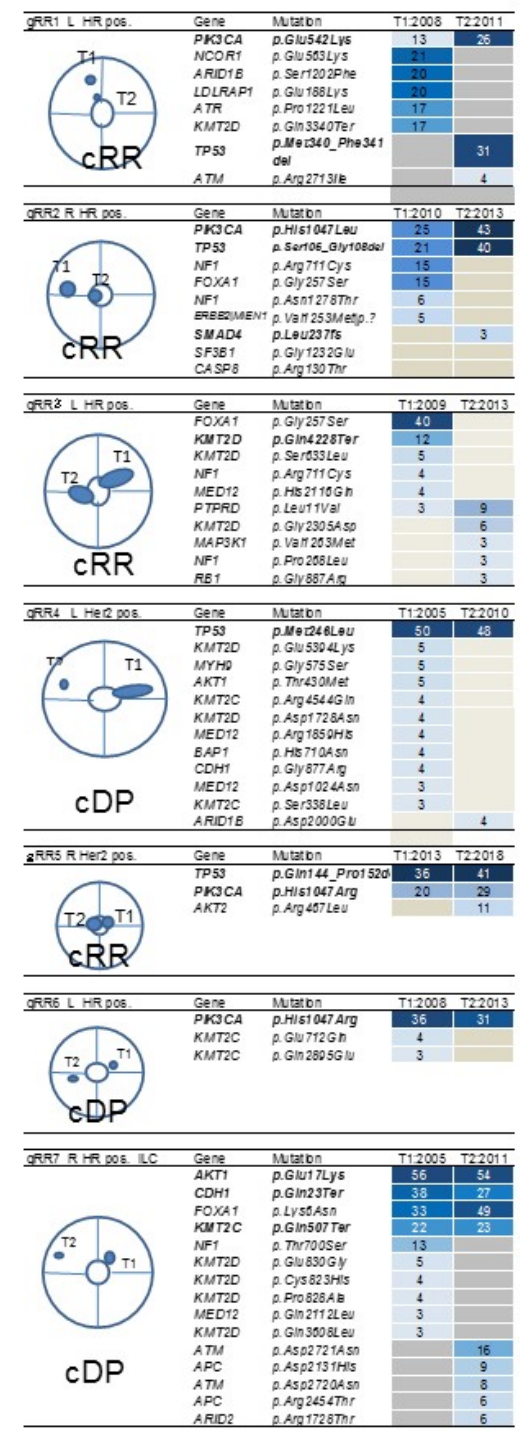

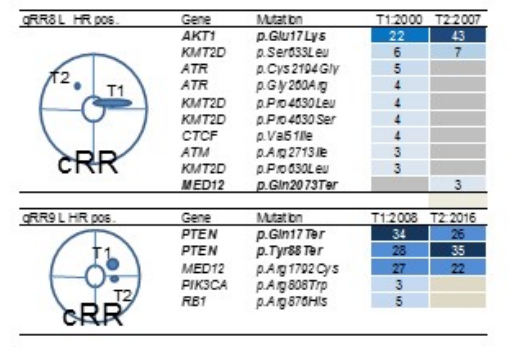
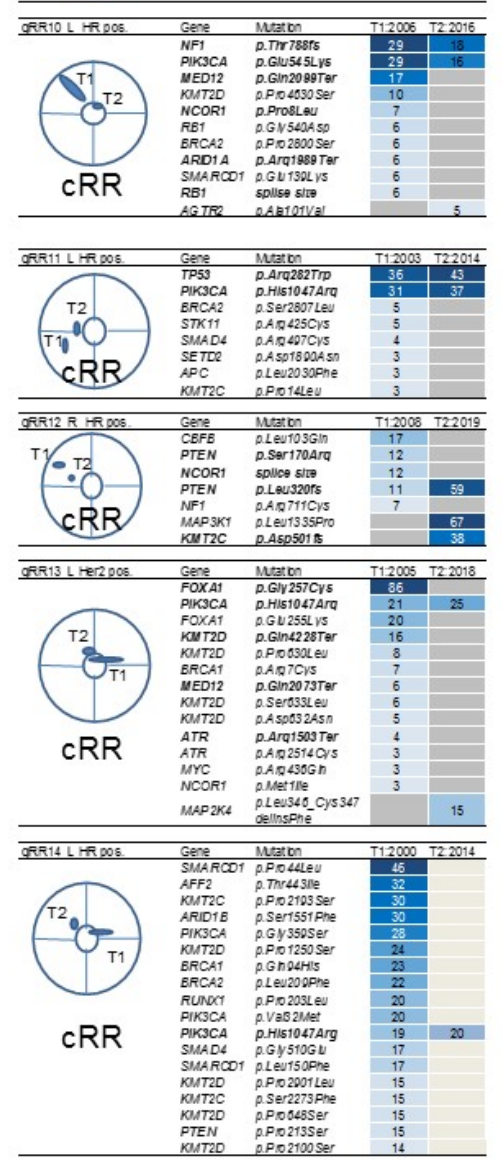

Fig. $2 b$

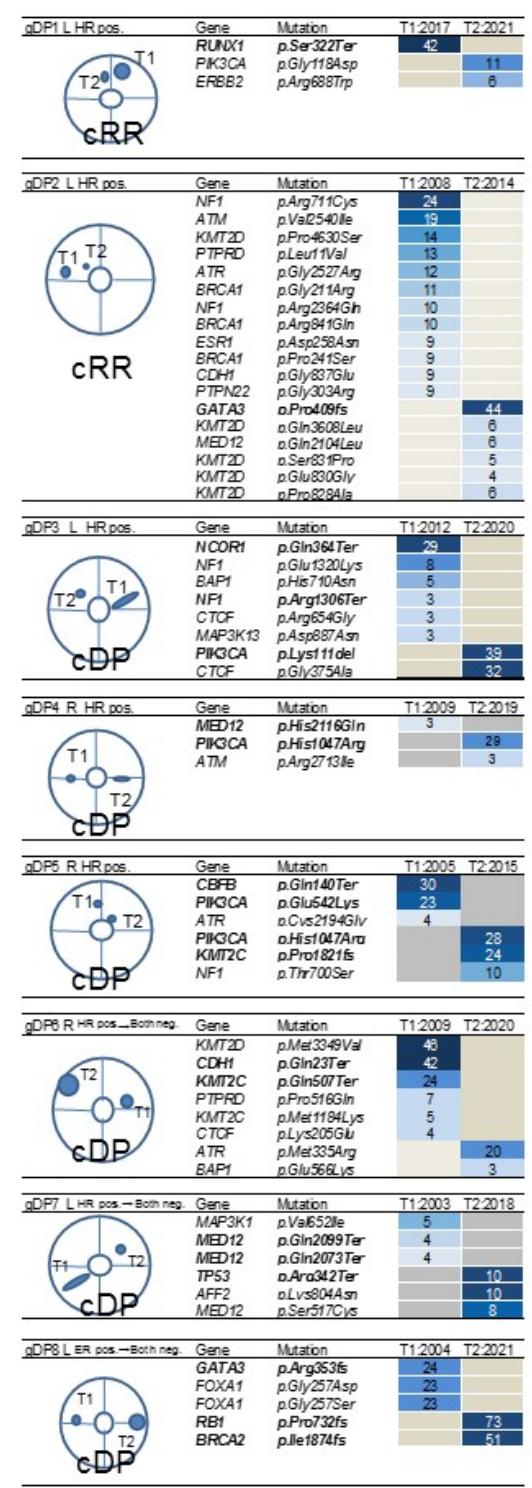

\section{Figure 2}

2a Genome profilling of primary breast cancer (PBC) and Ipsilateral breast tumor recurrence (IBTR ) a ; 14 cases of gRR.

14 cases were judged as genomic residual recurrence (gRR) because of shared mutations were identified between PBC (T1) and IBTR (T2). Oncogenic mutations are indicated by bold Italic. In gRR3, no common oncogenic mutation was found in T1 and T2, but a common PTPRD mutation was found and included in gRR.

b; 8 cases of gRR

2b 8 cases were judged as gDP because of absence of shared mutations between T1 and T2. 


\section{Supplementary Files}

This is a list of supplementary files associated with this preprint. Click to download.

- Table1submit.xlsx

- Table2asubmit.xlsx

- Table2bsubmit.xlsx

- Table3submit.xlsx 